\title{
Enterolith with a Stingray Spine Nidus in an Atlantic Bottlenose Dolphin (Tursiops truncatus)
}

\begin{abstract}
Leslie G. Burdett, ${ }^{1}$ and Carl A. Osborne ${ }^{2}{ }^{1}$ National Oceanic and Atmospheric Administration, National Ocean Service, Center for Coastal Environmental Health and Biomolecular Research, 219 Ft. Johnson Road, Charleston, South Carolina 29412, USA; ${ }^{2}$ Minnesota Urolith Center, Veterinary Clinical Sciences Department, University of Minnesota, College of Veterinary Medicine, 1352 Boyd Avenue, St. Paul, Minnesota 55108, USA;

${ }^{3}$ Corresponding author (email: Leslie.Burdett@ noaa.gov)
\end{abstract}

ABSTRACT: In March 2006, a dead, male bottlenose dolphin (Tursiops truncatus) was found in the salt marsh in Charleston, South Carolina, United States. During necropsy, an enterolith was found completely obstructing the intestinal lumen. Further examination of the enterolith revealed a stingray spine nidus. Most terrestrial enteroliths are composed primarily of struvite (magnesium ammonium phosphate); however, the majority of the enterolith discovered in the stranded dolphin was composed of calcium phosphate carbonate. This case provides an interesting comparison of the variation in the mineral composition between terrestrial and marine enteroliths.

Key words: Bottlenose dolphin, calcium phosphate, enterolith, magnesium ammonium phosphate, stingray spine, Tursiops truncatus.

Enteroliths are concretions found in the intestinal lumen and have been associated with intestinal obstructions in horses, cats, dogs, humans, and other large mammals (Raper, 1921; Milton and Axelrod, 1951; Lloyd et al., 1987; Crane et al., 1988; Hassel et al., 1997; Yuki et al., 2006). Multiple factors lead to these obstructions including diet, genetics, alkaline intestinal environments, and ingestion of foreign objects that cannot be digested, such as nails and other metal objects, as well as husks of oat and alfalfa, and hair. These foreign objects become the center, or nidus, of the stone and have been associated with the formation of enteroliths (Milton and Axelrod, 1951; Lloyd et al., 1987; Hassel et al., 1997; Hassel, 2002). In many cases, enteroliths consist of concentric layers of minerals deposited around a central nidus and, eventually, the progressive accumulation of the mineral layers results in partial or total obstruction of the intestinal lumen. Although enteroliths have been reported in a variety of terrestrial mammals, they have not been reported in bottlenose dolphins (Tursiops truncatus) or any other marine mammal.

On 12 March 2006, the carcass of a dead, male bottlenose dolphin was found in the salt marsh on the southeast side of the downtown peninsula in Charleston, South Carolina, USA $\left(32.78077^{\circ} \mathrm{N}\right.$, $\left.79.92422^{\circ} \mathrm{W}\right)$. The dolphin was $204 \mathrm{~cm}$ in length, and gross observation of the testes indicated that he was sexually immature. The dolphin was in poor body condition (code 4, Geraci and Lounsbury, 2005); $95 \%$ of his skin was missing, presumably as a result of extensive autolysis. At necropsy, the carcass was severely bloated, and many of the internal organs lacked consistency due to autolysis. Because of the extensive decomposition, only gross observations of the internal organs were possible. A small amount of reddish gelatinous material was observed in the fascia just dorsal to the right scapula, a copious amount of red-tinged fluid was observed in the thoracic cavity, bloody fluid filled the air passages of the right and left lung, and several black lesions were present on the serosal surface of the right lung. Orange viscous fluid was observed in the esophagus, a light brown milky fluid was found in the intestine, and the stomach was empty.

An enterolith was found approximately $50 \mathrm{~cm}$ anterior to the colon and measured $11 \times 3.2 \times 11 \mathrm{~cm}$. The enterolith was covered with an orange-colored clay-like material observed in the intestinal lumen. 


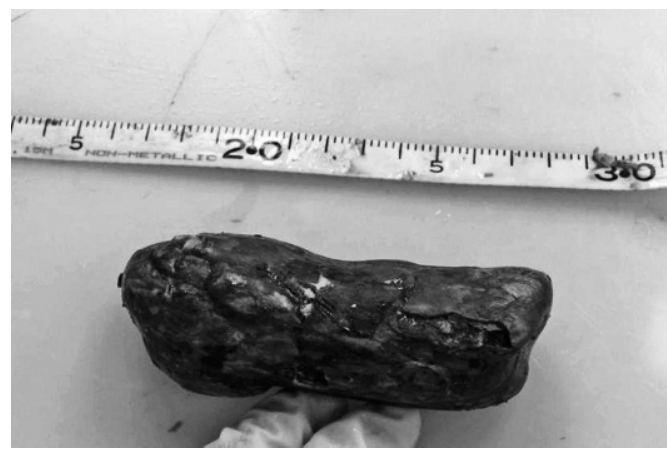

Figure 1. Enterolith from the intestine of a bottlenose dolphin stranded in South Carolina, United States.

The stone had a smooth texture and was brown-red in color (Fig. 1). Approximately $10 \mathrm{~cm}$ anterior to the enterolith, the intestinal wall was abnormally black in color for a length of approximately $15 \mathrm{~cm}$. A radiograph of the enterolith revealed that it was uniform in density; a nidus was not detected. However, dissection of the stone exposed a nidus surrounded by concentric layers of minerals (Fig. 2). Further evaluation of the nidus revealed that it was the spine from a stingray (Fig. 3).

The origin of the spine and its migration path could not be determined for this

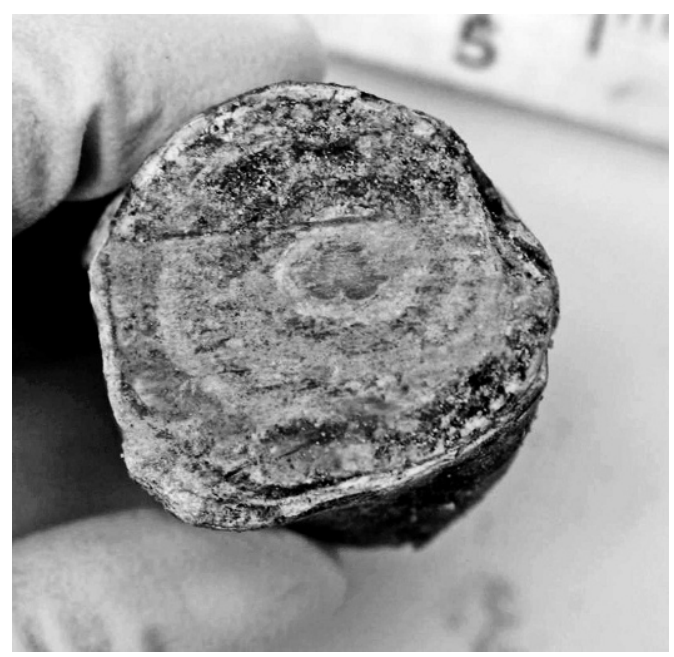

Figure 2. Concentric layers of minerals observed in a cross section of the enterolith described in Fig. 1.

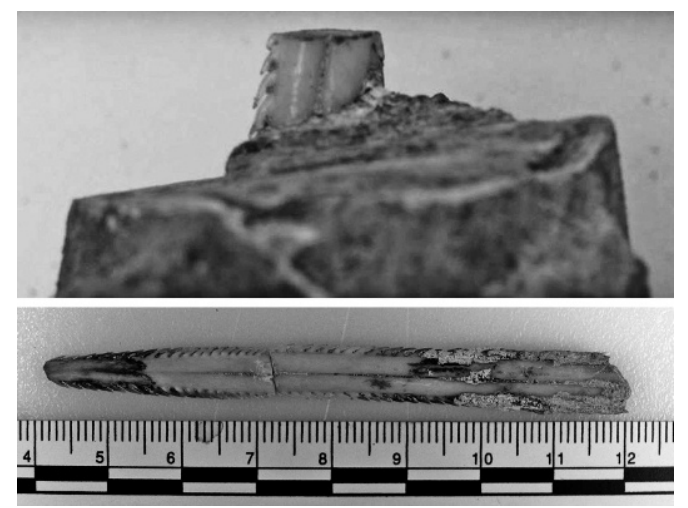

Figure 3. Stingray spine from Dasyatis americana found in the enterolith described in Fig. 1.

dolphin. A puncture wound was not visible on the epidermis, as most of the skin was missing from the dolphin, and a large amount of fluid was observed in the thoracic cavity; however, none was observed abdominally in the proximity of the enterolith. The only sign of trauma in the proximity of the enterolith was the $15-\mathrm{cm}$ section of black-colored intestine.

Embedded stingray spines are not uncommon in marine mammals. Case reports have described stingray penetration in the jaw, cranial rete mirabile, and hypaxial muscle near the esophagus in killer whales (Orcinus orca), where foraging on stingrays has been observed and ingestion of stingrays or their spines has been suggested to explain spine presence (Walsh et al., 1988; Visser, 1999; Duignan et al., 2000). In bottlenose dolphins, stingray spines have been reported in the pancreas, liver, and lungs (Walsh et al., 1988), vena cava (McLellan et al., 1996), and scapula (McFee et al., 1997). Evidence of epidermal puncture, or the cause of death, cannot always be determined because of extensive carcass decomposition due to postmortem autolysis; however, it is speculated that bottlenose dolphin death from stingray spine penetration could be caused by an adverse venomous reaction (Walsh et al., 1988; Duignan et al., 2000; Spanier et al., 2000), trauma from spine penetration (Walsh et al., 1988; 
McLellan et al., 1996; Duignan et al., 2000), or bacterial infection from the presence or internal migration of the spine (Walsh et al., 1988).

The barb was identified as belonging to the southern stingray (Dasyatis americana) (B. Roumillat, South Carolina Department of Natural Resources, pers. comm.), which range in size from 200 to $1,500 \mathrm{~mm}$ and prefer large coastal bays with moderate to high salinities (18-36 partial salinity units [psu]; Bigelow and Schroeder, 1953; Froese and Pauly, 2006). The southern stingray inhabits Atlantic waters from New Jersey to Brazil (Bigelow and Schroeder, 1953; Michael, 1993), a range which overlaps known bottlenose dolphin habitat (Reeves et al., 2002). In reports of stingray spines found in bottlenose dolphins, most were from the southern stingray or the Atlantic stingray (Dasyatis sabina) (Walsh et al., 1988, McLellan et al., 1996; McFee et al., 1997).

The spine in this study measured $8.0 \mathrm{~cm}$ in length and $0.8 \mathrm{~cm}$ at its greatest width (Fig. 3). Removal of the spine from the enterolith revealed that it was broken; only a piece of the spine was embedded in layers of minerals. Based on the size of the spine fragment embedded in the enterolith, the minimum size of this stingray would be $860 \mathrm{~mm}$ for males and $1,000 \mathrm{~mm}$ for females (Bigelow and Schroeder, 1953). This dolphin was $204 \mathrm{~cm}$; therefore, it is unlikely that the animal would prey upon a stingray almost half of its total length, or accidentally ingest a spine of that size.

The composition of the enterolith from this bottlenose dolphin was further examined at the Minnesota Urolith Center located at the University of Minnesota (College of Veterinary Medicine, St. Paul, Minnesota, USA). Examination of representative portions of the specimen by polarizing light microscopy and infrared spectroscopy revealed that $85 \%$ of the outer shell of the stone was composed of calcium phosphate carbonate, and the remaining $15 \%$ was composed of magne- sium ammonium phosphate (struvite). The largest layer of mineral that completely surrounded the nidus was composed of 95\% calcium phosphate carbonate and 5\% struvite. Additionally, a band within the internal portion of the enterolith consisted of $45 \%$ calcium phosphate carbonate and $55 \%$ brushite (calcium hydrogen phosphate dihydrate).

In a variety of species, examination of enteroliths by x-ray diffraction indicated that they varied in mineral composition; however, the primary mineral compound found in mammalian enteroliths was struvite (Milton and Axelrod, 1951; Taylor and Faure, 1983; Lloyd et al., 1987; Schiffman, 1998; Hassel, 2002). Other compounds that have been found in enteroliths from large mammals include brushite and newberyite (magnesium hydrogen phosphate trihydrate; Milton and Axelrod, 1951), whereas stones from the intestines of dogs have consisted of whewellite (calcium oxalate monohydrate) and weddellite (calcium oxalate dihydrate) (Milton and Axelrod, 1951). Calcium phosphate and calcium carbonate were found in an enterolith from a cat (Yuki et al., 2006). In humans, enteroliths composed of calcium oxalate (Crane et al., 1988), magnesium ammonium phosphate, calcium phosphate, and calcium carbonate (Raper, 1921) have been observed. Struvite has been found in calculi from the vagina of a bottlenose dolphin (McFee and Osborne, 2004) and from the penis of a pygmy sperm whale (Kogia breviceps) (Harms et al., 2004), whereas calcium phosphate compounds have been found in calculi from the vagina of other delphinid species (Sawyer and Walker, 1977; Woodhouse and Rennie, 1991).

Only a relatively small portion of the enterolith from this bottlenose dolphin was composed of struvite. The majority of the stone consisted of calcium phosphate carbonate, which is similar to the composition of vaginal calculi observed in other delphinid species (Sawyer and Walker, 1977; Woodhouse and Rennie, 1991). 
Calcium phosphate compounds comprise the primary type of mineral found in mammalian bone; therefore, Woodhouse and Rennie (1991) speculated that bone remnants from nonexpelled aborted fetuses may play a pivotal role in vaginal calculi formation. In a similar manner, perhaps bone remnants from fish remains in the stomach contribute to a chemical environment that favors the deposition of calcium carbonate, rather than the deposition of struvite, around foreign objects.

In conducting necropsies on stranded marine mammals, scientists search for a cause of death. The internal organs and vital tissues of stranded carcasses should be closely examined for the presence of stingray spines or evidence of spine migration. In some cases, the penetration of major organs by stingray spines, and the associated infection, may contribute to the animal's cause of death. While we may not be able to determine how the stingray spine entered the lumen of the intestine, we know that foreign objects in bottlenose dolphins can result in enterolithiasis. Unfortunately, the state of decomposition for this animal prevented determination of the cause of death; however, it is likely that intestinal obstruction due to enterolithiasis contributed to the demise of this animal.

The authors would like to thank R. Sayre for assistance with the stranding response and necropsy of this bottlenose dolphin; F. Townsend for his veterinary expertise; B. Roumillat Sr. for species identification of the stingray spine and for comments on this paper; B. Roumillat Jr. for radiographs of the enterolith; J. Adams for his assistance with geographic information systems; and W. McFee, J. Bemiss, and P. Fair for National Ocean Service internal review. This publication does not constitute an endorsement of any commercial product or intend to be an opinion beyond scientific or other results obtained by the National Oceanic and Atmospheric Administration (NOAA). No reference shall be made to NOAA, or this publication furnished by NOAA, to any advertising or sales promotion which would indicate or imply that NOAA recommends or endorses any proprietary product mentioned herein, or which has as its purpose an interest to cause the advertised product to be used or purchased because of this publication.

\section{LITERATURE CITED}

Bigelow, H. B., and W. C. Schroeder. 1953. Sawfishes, guitarfishes, skates and rays. In Fishes of the Western North Atlantic. Part 2, H. B. Bigelow and W. C. Schroeder (eds.). Sears Foundation for Marine Research, Yale University, New Haven, Connecticut, 514 pp.

Crane, P. W., P. R. Crocker, D. A. Levison, and O. J. A. Gilmore. 1988. Enterolith ileus. Journal of the Royal Society of Medicine 81: 292294.

Duignan, P. J., J. E. B. Hunter, I. N. Visser, G. W. Jones, AND A. Nutman. 2000. Stingray spines: A potential cause of killer whale mortality in New Zealand. Aquatic Mammals 26: 143-147.

Froese, R. and D. Pauly (eds.). 2006. FishBase. World Wide Web electronic publication, www. fishbase.org, version (10/2006).

Geraci, J. R., and V. J. Lounsbury. 2005. Marine mammals ashore: A field guide for strandings, 2nd Edition, N. Yates (ed.). National Aquarium in Baltimore, Baltimore, Maryland, $371 \mathrm{pp}$.

Harms, C. A., R. Lopiccolo, D. S. Rotstein, and A. A. Hohn. 2004. Struvite penile urethrolithiasis in a pygmy sperm whale (Kogia breviceps). Journal of Wildlife Diseases 40: 588-593.

Hassel, D. M. 2002. Enterolithiasis. Clinical techniques in equine practice 1: 143-147.

- J. R. Snyder, D. M. Langer, C. M. Drake, and T. B. Yarbrough. 1997. Equine enterolithiasis: A review and retrospective analysis of 900 cases (1973-1996). Soft Tissue Surgery 43: 246-247.

Lloyd, K., H. F. Hintz, J. D. Wheat, and H. F. SChryver. 1987. Enteroliths in horses. Cornell Veterinarian 77: 172-186.

McFee, W. E., And C. A. Osborne. 2004. Struvite calculus in the vagina of a bottlenose dolphin (Tursiops truncatus). Journal of Wildlife Diseases 40: 125-128.

McFee, W., H. Root, R. Friedman, and E. Zolman. 1997. A stingray spine in the scapula of a bottlenose dolphin. Journal of Wildlife Diseases 33: 921-924.

Mclellan, W. A., V. G. Thayer, and D. A. Pabst. 1996. Stingray spine mortality in a bottlenose dolphin, Tursiops truncatus, from North Carolina waters. Journal of the Elisha Mitchell Scientific Society 112: 98-101.

Michael, S. 1993. Reef sharks and rays of the world. 
A guide to their identification, behavior and ecology. Sea Challengers, Monterey, California, $107 \mathrm{pp}$.

Milton, C., and J. M. Axelrod. 1951. Calculi and other stones found in mammals. Journal of Mammology 32: 139-154.

Raper, H. S. 1921. A human enterolith containing choleic acid. Biochemical Journal 15: 49-52.

Reeves, R. R., B. S. Stewart, P. J. Clapham, and J. A. Powell. 2002. Common bottlenose dolphin. In National Audubon Society guide to marine mammals of the world. Alfred A. Knopf, New York, New York, pp. 358-361.

SAWYer, J. E., AND W. A. Walker. 1977. Vaginal calculi in the dolphin. Journal of Wildlife Diseases 13: 346-348.

SCHiffman, P. 1998. Mineralogical investigation of an enterolith from a Grant's zebra. Environmental Geochemistry and Health 20: 103-112.

Spanier, E., O. Goffman, D. Kerem, and K. Lavalli. 2000. Injury of an Indian Ocean bottlenose dolphin (Tursiops aduncus) in the Red Sea by a stingray spine. Aquatic Mammals 26: 196-201.

Taylor, K. S., and G. Faure. 1983. Geochemical study of an equine enterolith, Medina County, Ohio. Ohio Journal of Science 83: 54-59.

Visser, I. 1999. Benthic foraging on stingrays by killer whales (Orcinus orca) in New Zealand waters. Marine Mammal Science 15: 220-227.

Walsh, M. T., D. Beusse, G. D. Bossart, W. G. Young, D. K. Odell, and G. W. Patton. 1988. Ray encounters as a mortality factor in Atlantic bottlenose dolphins (Tursiops truncatus). Marine Mammal Science 4: 154-162.

Woodhouse, C. D., and C. J. Rennie. 1991. Observations of vaginal calculi in dolphins. Journal of Wildlife Diseases 27: 421-427.

Yuki, M., N. Sugimoto, K. Takahashi, H. Ohtsuka, N. Nishit, AND K. Suzuki. 2006. Enterolithiasis in a cat. Journal of Feline Medicine and Surgery 8: 349-352.

Received for publication 23 October 2007. 